\title{
Gundelia tournefortii Ekstraktlarının Antimikrobiyal Aktivitesi ve AMES/mikrozom Testi ile Antimutajenitesinin Belirlenmesi
}

\author{
Fatma Esen SARIGÜLLÜ ÖNALAN ${ }^{1 *} \quad$ Hatice Aysun MERCIMEK TAKCI ${ }^{2} \quad$ Filiz UÇAN TÜRKMEN $^{2}$ \\ ${ }^{{ }^{*}}$ Kilis 7 Aralık Üniversitesi Yusuf Şerefoğlu Sağllk Bilimleri Fakültesi Hemşirelik Bölümü, Kilis, Türkiye \\ ${ }^{2}$ Kilis 7 Aralık Üniversitesi Fen Edebiyat Fakültesi Moleküler Biyoloji ve Genetik Bölümü, Kilis, Türkiye
}

Atıf yapmak için: Sarıgüllü Önalan, F.E., Mercimek Takı, H.A. \& Uçan Türkmen, F. (2021). Gundelia tournefortii Ekstraktlarının Antimikrobiyal Aktivitesi ve AMES/mikrozom Testi ile Antimutajenitesinin Belirlenmesi. Anadolu Çev. ve Hay. Dergisi, 6(3), 428-433.

How to cite: Sarıgüllü Önalan, F.E., Mercimek Takı, H.A. \& Uçan Türkmen, F. (2021). Determinatin of Antimicrobial Activity and Antimutagenicity of Gundelia tournefortii Extracts with AMES/Microsome Test. J. Anatolian Env. and Anim. Sciences, 6(3), 428-433.

: https://orcid.org/0000-0002-1374-4338

: https://orcid.org/0000-0002-5394-4959

: https://orcid.org/0000-0002-3653-9433

*Sorumlu yazarın:

Fatma Esen SARIGÜLLÜ ÖNALAN

Kilis 7 Aralık Üniversitesi Yusuf Şerefoğlu

Sağlık Bilimleri Fakültesi Hemşirelik

Bölümü, Kilis, Türkiye

凶: esenonalan@kilis.edu.tr

Öz: Bu çalışmada ülkemizde özellikle Doğu Anadolu'da sıklıkla tüketilen Gundelia tournefortii (Kenger) bitkisinin genç saplarının AMES/mikrozom testi ile antimutajenik aktivitesinin ve antimikrobiyal aktivitesinin belirlenmesi amaçlanmıștır. Oda sıcaklığında ve nemsiz ortamda kurutma işlemi gerçekleştirilen kenger bitki ekstraktları su, metanol ve hekzan ile ekstrakte edilmiştir (1:10 (w/v)). Evaporatörde yoğunlaştırılan örnekler, son konsantrasyonları $1000 \mathrm{mg}$ $\mathrm{ml}^{-1}$ olacak şekilde metanol ile ekstrakte edilmiştir. Ekstraktların Bacillus cereus ATCC 11778, Staphylococcus aureus ATCC 25923, Escherichia coli ATCC 25922, Pseudomonas aeruginosa ATCC 27853, Salmonella typhimurium ATCC 14028 karş1 in vitro antimikrobiyal özellikleri araştırılmıştır. $1000 \mathrm{mg} \mathrm{ml}^{-1}$ metanol ekstraktının metisilin dirençli Staphylococcus aureus ATCC 25923 suşuna karş $15 \mathrm{~mm}$ çaplı antimikrobiyal etki gösterdiği saptanmıştır. Kenger bitkisinin su ekstraktlarının $21 \mathrm{mg} \mathrm{ml}^{-1}, 43 \mathrm{mg} \mathrm{ml}^{-1}, 87 \mathrm{mg} \mathrm{ml}^{-1}$ ve $175 \mathrm{mg} \mathrm{ml}^{-1}$ konsantrasyonlarının antimutajenik aktiviteleri Ames yöntemi ile tespit edilmiștir. $21 \mathrm{mg} \mathrm{ml}^{-1}$ konsantrasyondaki su ekstresinin S9 varlğında ve yokluğunda güçlü düzeyde antimutajenik aktivitesi belirlenmiştir.

Anahtar kelimeler: Ames/mikrozom testi, antimikrobiyal aktivite, antimutajenik aktivite, Gundelia tournefortii (Kenger).

\section{Determinatin of Antimicrobial Activity and Antimutagenicity of Gundelia tournefortii Extracts with AMES/Microsome Test}

*Corresponding author's: Fatma Esen SARIGÜLLÜ ÖNALAN Yusuf Serefoğlu Faculty of Health Sciences, Kilis 7 Aralık University, KILIS, Turkey $凶$ : esenonalan@kilis.edu.tr
Abstract: In this study, it was aimed to determine the antimutagenic activity by using the AMES/microsome test and antimicrobial activity of the young stems of the Gundelia tournefortii (Kenger) plant, which is frequently consumed in our country, especially Eastern Anatolia. The plant extracts, dried at room temperature by without humidity, were extracted with distilled water, methanol and hexane $(1: 10(\mathrm{w} / \mathrm{v}))$. After evaporation, the samples were extracted with methanol at final concentration of $1000 \mathrm{mg} \mathrm{ml}^{-1}$. In vitro antimicrobial properties of the extracts against Bacillus cereus ATCC 11778, Staphylococcus aureus ATCC 25923, Escherichia coli ATCC 25922, Pseudomonas aeruginosa ATCC 27853, Salmonella typhimurium ATCC 14028 were investigated. It was determined that $1000 \mathrm{mg} \mathrm{ml}^{-1}$ methanol extract had an antimicrobial effect with a diameter of $15 \mathrm{~mm}$ against methicillin resistant Staphylococcus aureus ATCC 25923 strain. Antimutagenic activities of $21 \mathrm{mg} \mathrm{ml}^{-1}, 43 \mathrm{mg} \mathrm{ml}^{-1}, 87 \mathrm{mg} \mathrm{ml}^{-1}$ ve $175 \mathrm{mg} \mathrm{ml}^{-1}$ concentrations of distilled water extracts of Kenger plant were determined by Ames method. The strong antimutagenic activity for $21 \mathrm{mg} \mathrm{ml}^{-1}$ water extract was observed in the presence and absence of S9.

Keywords: Ames/microsome test, antimicrobial activity, antimutagenic activity, Gundelia tournefortii (Kenger) 


\section{GİRIŞ}

3000'i endemik olmak üzere yaklaşık 12000 bitki taksonuna sahip ülkemiz bitki biyoçeşitliliği açısından oldukça zengindir. Özellikle besinsel ve fonksiyonel özelliklerinden dolayı yabani yenilebilir bitkiler geleneksel olarak halk arasında kullanılmaktadır (Konak vd., 2017). Yenilebilir kısımlarının vitamin, mineral ve besin elementleri açısından zengin olmasının yanı sıra yararlı fitokimyasal içerik miktarlarına göre antioksidan, antimikrobiyal, antiviral, antikarsinojenik, antiinflamatuar, anti-parazit ve antimutajenik gibi biyolojik aktiviteleri de ortaya konulmuş yabani bitkiler insan sağlığ açısından önemli rol oynamaktadır (Konak vd., 2017; Saraç vd., 2019).

Asteraceae familyasına ait Gundelia tournefortii kenger otu, kenger sakızı, sakız otu, çadır dikeni ve kanak sakızı gibi çeşitli adlarla bilinen yenilebilir yabani bir bitki türüdür. Kenger, ülkemizde Anadolu'da Karaman, Ermenek, Toros dağları (Gülek civarı), Bayburt, Elazığ, Antalya (Yayladağı), Gaziantep, Silifke, Diyarbakır vb. bölgelerde farklı rakımlarda yetişebilen ve enginara benzeyen başçı̆̆ı ve genç sapları nedeniyle sebze olarak yenilebilmekte, yem bitkisi olarak kullanılmakta ve gövdesinden sıan kıvamlı süt kenger sakızı olarak bilinmektedir (Karataş vd., 2014). Dondurma üretiminde iyi bir stabilizatör olarak kullanılmasına ek olarak, K, Ca, $\mathrm{P}, \mathrm{Na}, \mathrm{Fe}, \mathrm{Mg}$ ve $\mathrm{Zn}$ gibi mineraller, yağ asitleri, tokoferol ve sterolleri de içerdiğinden yüksek besinsel içeriğe sahiptir (Al-Kadhi vd., 2020; Okcu ve Kaplan, 2018; Karaaslan vd., 2014).

20-30 cm boyunda, tek tohumlu, dikenli, çok y1llık otsu bir bitki olan kenger bitkisinin vücut kısmı hepatoprotektif ve kan temizleyici olarak, Doğu Anadolu'da ise kuru tohumları vitiligo tedavisinde, taze tohumları idrar söktürücü olarak, tohumlar ve diğer kısımlar yüksek antioksidan potansiyele sahip olup halk arasında tıbbi olarak kullanılmaktadır (Özaltun ve Daştan, 2019; Saraç vd., 2019; Ceylan vd., 2019). Ayrıca, karaciğer iltihabı, hipoglisemik, safra yolu iltihabı, siroz, kabakulak, ishal, bronşit ve kronik karaciğer hastalıklarına karşı etkisi de bildirilmiştir (Haghi vd., 2011; Rafii vd., 2017; Saraç vd., 2019).

İnsanoğlunun yaşamı boyunca çevresinde karşılaştığı pek çok mutajenik ve karsinojenik ajanlara karşı genomun korunması oldukça hayati önem taşımaktadır. Genomun kendi onarım sistemleri dışında, bitkilerden elde edilen antioksidan, antimutajenik özelliğe sahip biyoaktif bileşenlerle desteklenerek korunması da mümkündür. Bu açıdan günümüzde yabani yenilebilir bitki türlerinin çoğu antimutajenik potansiyelleri yönünden araştırılmaktadır. Bu nedenle çalışmamızda Gundelia tournefortii (kenger) bitkisinin genç saplarına ait kısımlarının Ames/mikrozom testi ile antimutajenik aktivitesi ve antibakteriyel aktivitesinin belirlenmesi amaçlanmıştır. Ülkemizde kenger bitkisi ile yapılmış antimutajenite aktivite çalışmasının bulunmaması sebebiyle bu projemiz ilk rapor olma niteliğini taşımaktadır.

\section{MATERYAL VE METOT}

Bitki Ekstraktlarının Hazırlanması: Kenger, Gundelia tournefortii bitkisi Mart ve Nisan ayları boyunca Urfa il pazarından toplanmıştır. Elde edilen bitkiler oda koşullarında gölgede kesilip kurutulmuş ve analizlerde kullanılana kadar karanlık şişelerde muhafaza edilmiştir. Bitki kısımları ev tipi öğüücüde (Arçelik K 3104) toz haline getirilmiştir. Ekstraksiyon için $30 \mathrm{gr}$ toz haline getirilmiş kenger bitkisi kullanılmıştır. 72 saat oda sıcaklığında çalkalamalı koşullarda su, hekzan ve metanol çözücüleri (1:10 (w/v)) kullanılarak ekstraksiyon basamağ1 sürdürülmüştür. Ekstraksiyon işlemi tamamlanan örnekler filtre kağıdından (Whatman filter paper No.1) süzülmüş ve çözücülerin uzaklaştırılması için evaporatör kullanılmıştır. Evaporasyon sonrası örneklerin son konsantrasyonu 1000 $\mathrm{mg} \mathrm{ml} \mathrm{m}^{-1}$ olacak şekilde metanol içerisinde süspanse edilmiştir. Antimutajenite çalışmaları için ise sadece su fazı ekstresi test edilmiştir. Antimikrobiyal analizler için $1000 \mathrm{mg} \mathrm{ml}^{-1}$ hekzan, saf su ve metanol ekstraktları kullanılmıştır. Ekstraktlar biyolojik aktivite analizlerine kadar renkli şişelerde $-20^{\circ} \mathrm{C}$ 'de stoklanmıştır.

Antibakteriyel Analizler: Kenger bitkisi ekstraktlarının bakterilere karşı biyolojik aktivitesini belirlemek amacıyla Kirby-Bauer disk difüzyon yöntemi kullanılmıştır (Bauer vd., 1966). Çalışmada, laboratuvarımız kültür koleksiyonunda bulunan standart bakteriler (Bacillus cereus ATCC 11778, Staphylococcus aureus ATCC 25923, Escherichia coli ATCC 25922, Pseudomonas aeruginosa ATCC 27853, Salmonella typhimurium ATCC 14028) test edilmiştir. Bakterilere karşı belirlenecek aktivite için CLSI standartlarına uygun olarak Mueller Hinton Agar (MHA) besiyerleri kullanılmıştır. McFarland 0,5 standart bulanıklığında bakteri süspansiyonları hazırlanmış ve steril eküvyon çubuğu ile Mueller Hinton Agar yüzeyine inoküle edilmiştir. $6 \mathrm{~mm}$ çaplı steril blank disklere her bir kenger ekstrelerinden $10 \mu \mathrm{L}$ emdirilip steril penset yardımı ile agar yüzeyine eşit aralıklarla yerleştirilmiştir. Escherichia coli, Salmonella typhimurium ve Bacillus cereus için Tetrasiklin (30 mcg/disk); Staphylococcus aureus için Metisilin (5 mcg/disk); Pseudomonas aeruginosa için Polimiksin B (300 unite/disk) antibiyotikleri standart olarak kullanılmıştır. Negatif kontrol olarak steril blank disklere $10 \mu \mathrm{L}$ metanol emdirilmiştir. $37^{\circ} \mathrm{C}$ 'de $18-24$ saat 
inkübasyonu takiben disklerin etrafinda bakterilerin üremediği şeffaf zonların varlığı incelenmiştir.

Antimutajenite Analizleri: Maron ve Ames (1983) tarafindan geliştirilen Salmonella / mikrozom deneyi, kenger sulu ekstraktının antimutajenitesini saptamak için analiz edilmiştir. Analiz öncesi Salmonella typhimurium TA98 (HisD3052, pKm101, rfa, uvrB) ve TA100 (HisG46, pKm101, rfa, uvrB) suşlarının mutajen özellikleri test edilmiştir. Sitotoksisite analizi için $21 \mathrm{mg}$ $\mathrm{ml}^{-1}, 43 \mathrm{mg} \mathrm{ml}^{-1}, 87 \mathrm{mg} \mathrm{ml}^{-1}, 175 \mathrm{mg} \mathrm{ml}^{-1} \mathrm{mg} /$ plak kenger konsantrasyonları kullanılmıştır. Sitotoksik dozun belirlenmesi için, $100 \mu \mathrm{L}$ kenger ektsraktı ve gece boyunca

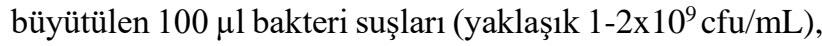
$2 \mathrm{~mL}$ üst agar içeren test tüpleriyle karıştırılmış ve Nutrient agar plağına dökülmüştür. $37^{\circ} \mathrm{C}$ de $24-72$ saat inkübe edilen plaklarda test ve kontrol plağındaki koloni sayısı karşlaştırılarak toksik olmayan doz tespit edilmiştir. Mutajenite deneyi, seçilen dozlarla sürdürülmüştür.

Kenger bitkisinin antimutajenitesi karaciğer S9 fraksiyonun varlığında ve yokluğunda test edilmiştir. Karaciğer S9 karışımı, Ames tarafindan açıklanan prosedüre göre hazırlanmıştır. (Maron ve Ames, 1983). Tüm testlerde, suşlara göre negatif kontroller (damıtılmış su) ve pozitif kontroller (S9 yokluğunda TA100 için sodyum azid $(5 \mu \mathrm{g} / \mathrm{plak})$, TA 98 suşu için 4-nitro-ofenilendiamin $\left(5 \mu \mathrm{g}\right.$ plak $\left.^{-1}\right)$; S9 varlığında TA100 için sodyum azid ( $\left.5 \mu \mathrm{g} \mathrm{plak}^{-1}\right)$, TA98 suşu için 2-Aminofloren $\left.\left(7.5 \mu \mathrm{g} \mathrm{plak}^{-1}\right)\right)$ pozitif direkt mutajen olarak kullanılmıştır (Ekmekçi, 2010).

$100 \mu \mathrm{l}$ pozitif mutajen madde ve $100 \mu \mathrm{l}$ gecelik bakteri kültürü (yaklaşık 1-2x109 $\mathrm{cfu} / \mathrm{mL}$ ) top agara ilave edilmiştir. Tüpler karıştırılarak MGA besiyerlerine dökülmüş ve $37^{\circ} \mathrm{C}$ 'de $48-72$ saat inkübe edilmiştir. Inkübasyon sonrası koloni sayımı yapılmıştır. Negatif ve pozitif kontroller de deneye paralel olarak yapılmıştır. Pozitif kontrol için $500 \mu$ l sodyum-fosfat tamponu+100 $\mu \mathrm{l}$ pozitif mutajen madde $+100 \mu 1$ bakteri kültürü top agara ilave edilmiștir. Negatif kontrol için $500 \mu 1$ sodyum-fosfat tamponu $+100 \mu \mathrm{l}$ su veya $\mathrm{DMSO}+100 \mu$ l bakteri kültürü top agara ilave edilmiştir. S9 yokluğundaki tüm işlemlerin aşamaları aynı şekilde yürütülmüştür. Sadece farklılık olarak S9 yokluğunda top agara eklenen $500 \mu 1$ fosfat tamponu yerine $500 \mu \mathrm{l}$ S9 karışımı eklenmiştir. Tüm analizler 3 tekrarlı yürütülmüștür.

\section{BULGULAR VE TARTISMA}

Kenger bitkisinin $1000 \mathrm{mg} \mathrm{ml}^{-1}$ hekzan, saf su ve metanol ekstraktlarının standart test izolatları (Bacillus cereus ATCC 11778, Staphylococcus aureus ATCC 25923, Escherichia coli ATCC 25922, Pseudomonas aeruginosa ATCC 27853, Salmonella typhimurium ATCC 14028) üzerindeki antimikrobiyal aktivitesi Tablo 1 'de verilmiştir.
Tablo 1. Kenger bitkisinin antibakteriyel aktivitesi (mm cinsinden).

Table 1. Antibacterial activity of the Kenger (terms of mm).

\begin{tabular}{|c|c|c|c|c|c|}
\hline & $\begin{array}{c}\text { Negatif } \\
\text { Kontrol } \\
\text { Negative } \\
\text { Control } \\
\end{array}$ & $\begin{array}{l}\text { Pozitif } \\
\text { Kontrol } \\
\text { Positive } \\
\text { Control } \\
\end{array}$ & $\begin{array}{c}\text { Su } \\
\text { Water }\end{array}$ & $\begin{array}{l}\text { Hekzan } \\
\text { Hexan }\end{array}$ & $\begin{array}{c}\text { Metanol } \\
\text { Methanol }\end{array}$ \\
\hline $\begin{array}{l}\text { S. aureus } \\
\text { ATCC } 25923\end{array}$ & - & - & - & - & $15 \pm 0$ \\
\hline $\begin{array}{l}\text { P.aeruginosa } \\
\text { ATCC } 27853\end{array}$ & - & $15 \pm 0$ & - & - & - \\
\hline $\begin{array}{l}\text { B. cereus } \\
\text { ATCC } 11778\end{array}$ & - & $28 \pm 2$ & - & - & - \\
\hline $\begin{array}{l}\text { S.typhimirum } \\
\text { ATCC } 14028\end{array}$ & - & $19 \pm 2$ & - & - & - \\
\hline $\begin{array}{l}\text { E. coli } \\
\text { ATCC } 25922\end{array}$ & - & $17,5 \pm 0,05$ & - & - & - \\
\hline
\end{tabular}

Tablodaki verilere göre Kenger bitkisinin sadece test mikroorganizmalarından Staphylococcus aureus ATCC 25923 suşu üzerinde metanol ekstraktının antibakteriyel aktivite gösterdiği belirlenmiştir. 2 . dereceden bakteriyemi etkeni ve hastane enfeksiyonu açısından önemli bir enfeksiyöz bakteri olan metisiline karşı dirençli $S$. aureus üzerinde gözlenen antibakteriyel aktivite metanol ekstraktının biyolojik etkinliğine işaret etmektedir.

Kenger bitkisinin su ve hekzan ekstraktlarının denenen test organizmaları üzerinde herhangi bir antimikrobiyal aktivitesi saptanamamıştır (Şekil 2).

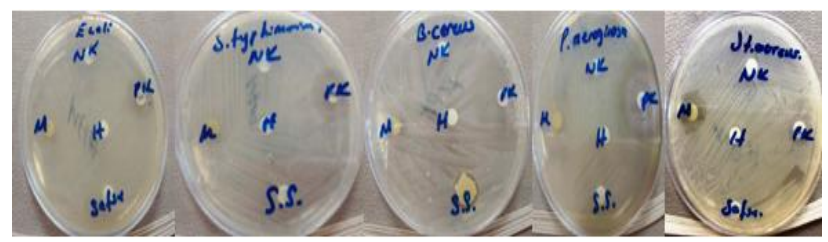

Şekil 2. Standart izolatlara karşı kenger bitki ekstratlarının antibakteriyel etkisi.

Figure 2. Antibacterial effect of kenger plant extracts against standard isolates.

Asadi-Samani vd., (2013) tarafindan Gundellia sp. türü üzerinde yapılan çalışmada, metanol ekstraktının çeşitli mikroorganizmalara karşı antimikrobiyal etkinlikleri bildirilmiştir. Saraç vd., (2019) kenger tohumu su ekstraktının bazı bakteriler üzerindeki etkisini inceledikleri çalışmada, 8 farklı mikroorganizmaya karşı zayıf nitelikte aktivite saptanırken çalışmamıza benzer olarak sadece $S$. aureus ATCC 29213 bakterisi üzerinde $0,3125 \mathrm{mg} / \mathrm{mL}$ değeriyle orta düzeyde bir etkinliğin olduğu gözlenmiştir. 8 adet standart suş üzerinde test edilen diğer bir çalışmada ise kenger bitkisinin kök, yaprak ve uçucu yağ sulu ekstrelerinin antimikrobiyal aktivitesi incelenmiştir. Çalışmamızın sonuçlarını destekler nitelikte test mikroorganizmaları üzerinde genelde zayıf ve önemsiz aktivite belirlenirken, sadece S. aureus ATCC 29213 suşuna karşın 1lımlı düzeyde $(0,5 \mathrm{mg} / \mathrm{mL})$ etki tespit edilmiştir (Özaltun ve Daştan, 2019). Kenger bitkisinin tüm kısımları ile yapılan diğer bir çalışmada ise, çoklu ilaç direnci gösteren Escherichia coli ve Pseudomonas 
aeruginosa'ya karşı antibakteriyel aktivite gözlenmiştir. Ancak bu aktivitenin penisilin $\mathrm{G}$ ve eritomisin ile kenger bitkisinin kombinasyonu sonunda belirlendiği rapor edilmiştir (Darwish ve Aburjai, 2010). Diğer bir çalışmada, kenger bitkisinin metanolik ekstraktlarının farklı antibiyotiklerle kombinasyonu ile dirençli $S$. aureus suşu üzerinde antibakteriyel aktivite gözlenmiş̧tir (Darwish vd., 2002).

Literatür çalışmaları ve projemizin sonuçları bazı bitki bileşenlerinin dirençli standart suşları üzerindeki antibakteriyel etkinliğinin yapısal farklılıklardan dolayı önemli düzeyde değişiklik gösterdiğini vurgulamaktadır.

Kenger sulu faz ekstresinin antimutajenite aktivitesinin belirlenmesi için öncelikle suşların mutant karakterleri ve kendiliğinden geri dönen koloni sayısı test edilmiştir. S. typhimurium TA98 ve TA100 suşlarının kendiliğinden geri dönen koloni sayısı aşağıdaki Tablo 2'de belirtildiği gibidir. $\mathrm{Bu}$ kendiliğinden geri dönen koloni sayısı her suş için olması gereken limitler aralığında bulunmuştur.

Tablo 2. S. typhimurium TA98 ve TA100 suşlarının kendiliğinden geri dönen koloni sayısı.

Table 2. Number of spontaneously returning colonies of $S$. typhimurium TA98 and TA 100 strains.

\begin{tabular}{lcc}
\hline Suşlar & Referans değerleri & $\begin{array}{c}\text { Kendiliğinden geriye } \\
\text { dönen koloni sayısı }\end{array}$ \\
\hline S. typhimurium TA98 & $20-50$ & 30,5 \\
S. typhimurium TA100 & $80-200$ & 168,5 \\
\hline
\end{tabular}

Antimutajenite deneylerinde kenger bitkisinin 21 $\mathrm{mg} \mathrm{ml} \mathrm{ml}^{-1}, 43 \mathrm{mg} \mathrm{ml}^{-1}, 87 \mathrm{mg} \mathrm{ml}^{-1}$ ve $175 \mathrm{mg} \mathrm{ml}^{-1}$ konsantrasyonlarındaki su ekstraksiyonları çalışıldı. Elde edilen verilere göre kontrol plaklarındaki koloni sayıları ve kenger bitkisinin bu konsantrasyonlarındaki koloni sayıları sayılamayacak kadar fazla olduğundan kenger bitkisinin bu konsantrasyonlarının sitotoksik etkilerinin olmadığı belirlendi.

Pozitif kontrollerin mutajenite oranları \%100 (yani $\% 0$ antimutajenite) kabul edilerek, kenger bitki ekstraktlarının antimutajenite oranları $[(\mathrm{A}-\mathrm{B}) /(\mathrm{A}-\mathrm{C})] \mathrm{x} 100$ formülüne göre hesaplanmıştır. $(\mathrm{A}=$ Bakteri+mutajen içeren besiyerinde geri dönen koloni sayısını; $\mathrm{B}=$ Bakteri+mutajen+ekstraktı içeren besiyerinde geri dönen koloni sayısını; $\mathrm{C}=$ Sadece bakteri içeren besiyerinde geri dönen koloni sayısını ifade etmektedir). İnhibisyonun aktivite yok veya zayıf antimutajenite olarak kabul edilmesi \%0-25 aralığı baz alınarak, orta derece antimutajenite için \%26-40 aralığı baz alınarak ve güçlü antimutajenite için ise $\% 40$ ve üzeri aralık baz alınmıştır (Uysal vd., 2016).

Kenger bitki ekstraktlarının antimutajenite test sonuçları Tablo 3 ve 4'de verilmiştir. Kenger bitki ekstraktlarının antimutajenik etkisi plak başına düşen revertant koloni sayılarının ortalaması ve bilinen mutajenlere karşı belirlenen \% inhibisyon oranları değerlendirilerek belirlenmiştir. TA98 suşu üzerinde S9 yokluğunda sadece $21 \mathrm{mg} \mathrm{ml}^{-1}$ kenger ekstraktları orta dereceli $(\% 38,41)$ antimutajenik aktivite gösterirken diğer konsantrasyonların zayıf antimutajenik etki gösterdiği gözlenmiştir. TA100 suşu üzerinde ise S9 yokluğunda 87 ve 43 kenger ekstraktları orta dereceli (\%28-36) antimutajenik aktivite gösterirken $21 \mathrm{mg} \mathrm{ml}^{-1}$ kenger ekstraktında ise güçlü antimutajenik aktivite $(\% 43,21)$ tespit edilmiştir.

S9 varlığında ise TA98 suşu üzerinde test edilen kenger konsatrasyonlarının tümü için \% inhibisyonun arttığ 1 saptanmıştır. $21 \mathrm{mg} \mathrm{ml}^{-1}$ kenger konsantrasyonunda S9 yokluğunda belirlenen orta dereceli $(\% 38,41)$ inhibisyon, S9 varlığında ise güçlü antimutajenik aktivite (\%44,87) ile sonuçlanmıştır. S9 varlığında TA100 suşuna karşın etkinliğin $21 \mathrm{mg} \mathrm{ml}^{-1}$ ve $43 \mathrm{mg} \mathrm{ml}^{-1}$ kenger konsantrasyonlarında artış gösterdiği tespit edilmiş olup, $87 \mathrm{mg} \mathrm{ml}^{-1}$ ve $175 \mathrm{mg} \mathrm{ml}^{-1}$ konsantrasyonlarda \% inhibisyonda azalma gözlenmiştir. Buna göre S9 varlığında TA100 suşu için en yüksek mutajen inhibitör etki \%63,35 güçlü antimuajenik aktvite ile $21 \mathrm{mg} \mathrm{ml}^{-1}$ kenger konsantrasyonunda rastlanmıştır.

Analizlerimizin sonuçları söz konusu antimutajenik aktivitenin madde konsantrasyonu artışına bağlı olarak \% inhibisyonun artmadığını ortaya koymaktadır. Buna göre her iki suş için S9 varlığında ve yokluğunda en güçlü aktivite $21 \mathrm{mg} \mathrm{ml}^{-1}$ kenger konsantrasyonunda gözlenmiştir.

Kanser, günümüzde endüstriyel dünyada ölümlerin ana nedenlerinden biri olarak kabul edilmektedir. Bilim adamları, DNA dizisi ve sürekliliğindeki genetik materyalin hasar görmesi, genlerdeki mutasyon ve kromozomal yapılardaki diğer genetik değișikliklerin karsinogenezde önemli rol oynadığına inanmaktadır. Günlük yaşamda antimutajen ve antikarsinojen kullanımı, insan kanserini ve genetik hastalıkları önlemede en etkili prosedür olarak görülmektedir (Sarac, 2015).

Bitki türlerinin ortaya çıkardığı antimutajenik özellikler, insan sağlığında çok çeşitli ileriye dönük uygulamalara sahiptir. Aktif bişenler içeren bitkisel ilaçlar DNA'ya elektrofil (örneğin, serbest radikaller gibi) saldırısının yaşlanma ve kanser gibi yaygın sonuçlarına karşı koruma sağlamak için geliştirilmektedir. Kanserin ortaya çıkma oranı dünya çapında artmakta olup, kemopreventif veya kemoprofilaksi bileşiklerinin belirlenmesi kanser riskini azaltma çabasında önemlidir. Antimutajenite gösteren bir bitki özütü, bir antikarsinojen değildir; ancak, bu tür amaçlar için potansiyel adayların bir göstergesidir (Sarac, 2015). 
Tablo 3. Kenger bitki ekstraktlarının S9 yokluğunda TA98 ve TA100 suşları üzerinde belirlenen antimutajenik etkileri.

Table 3. The antimutagenic effects of Kenger extracts on TA98 and TA100 strains in the absence of S9.

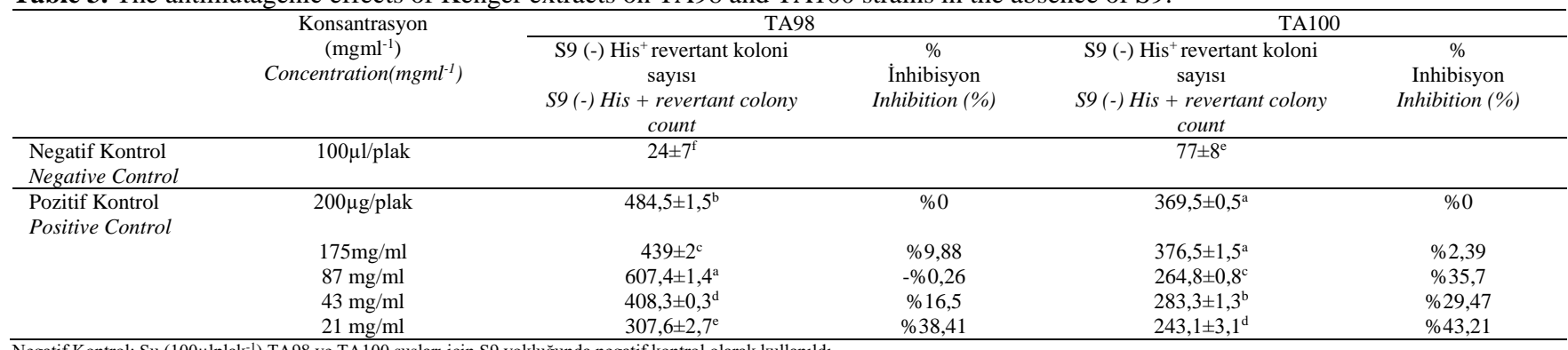

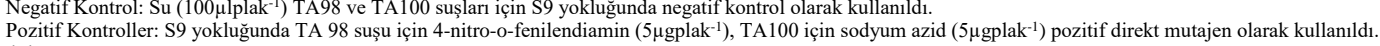

${ }^{\text {abcde } A y n ı ~ s u ̈ t u n d a k i ~ f a r k l ı ~ h a r f l e r e ~ s a h i p ~ g r u p l a r ~ a r a s ı n d a k i ~ f a r k ~ i s t a t i s t i k s e l ~ o l a r a k ~ o ̈ n e m l i d i r ~}(\mathrm{p}<0,05)$.

Tablo 4. Kenger bitki ekstraktlarının S9 varlığında TA98 ve TA100 suşları üzerinde belirlenen antimutajenik etkileri.

Table 4. Antimutagenic effects of Kenger extracts on TA98 and TA100 strains in the presence of S9.

\begin{tabular}{|c|c|c|c|c|c|}
\hline & \multirow{2}{*}{$\begin{array}{c}\text { Konsantrasyon } \\
\left(\mathrm{mgmL}^{-1}\right)\end{array}$} & \multicolumn{2}{|c|}{ TA98 } & \multicolumn{2}{|c|}{ TA 100} \\
\hline & & $\begin{array}{c}\mathrm{S} 9(+) \mathrm{His}^{+} \text {revertant koloni } \\
\text { say1s } 1 \\
S 9(+) \text { His }+ \text { revertant } \\
\text { colony count }\end{array}$ & $\begin{array}{l}\text { \% İnhibisyon } \\
\text { Inhibition (\%) }\end{array}$ & $\begin{array}{c}\text { S9 (+) His }{ }^{+} \text {revertant koloni } \\
\text { sayis } 1 \\
S 9(+) \text { His }+ \text { revertant } \\
\text { colony count } \\
\end{array}$ & $\begin{array}{l}\text { \% İnhibisyon } \\
\text { Inhibition (\%) }\end{array}$ \\
\hline $\begin{array}{l}\text { Negatif Kontrol } \\
\text { Negative Control }\end{array}$ & $100 \mu 1 /$ plak & $43 \pm 3^{f}$ & - & $106 \pm 25^{\mathrm{e}}$ & - \\
\hline $\begin{array}{l}\text { Pozitif Kontrol } \\
\text { Positive Control }\end{array}$ & $200 \mu \mathrm{g} /$ plak & $632,5 \pm 17,5^{\mathrm{a}}$ & - & $347,5 \pm 5,5^{\mathrm{a}}$ & - \\
\hline & $\begin{array}{l}175 \mathrm{mg} / \mathrm{mL} \\
87 \mathrm{mg} / \mathrm{mL} \\
43 \mathrm{mg} / \mathrm{mL} \\
21 \mathrm{mg} / \mathrm{mL}\end{array}$ & $\begin{array}{c}593,5 \pm 19,5^{\mathrm{b}} \\
538,5 \pm 1,5^{\mathrm{c}} \\
495,5 \pm 16,5^{\mathrm{d}} \\
368 \pm 9^{\mathrm{e}}\end{array}$ & $\begin{array}{l}\% 6,61 \\
\% 15,95 \\
\% 23,24 \\
\% 44,87\end{array}$ & $\begin{array}{c}343 \pm 9^{\mathrm{a}} \\
296,5 \pm 3,5^{\mathrm{b}} \\
246 \pm 3^{\mathrm{c}} \\
194,5 \pm 6,5^{\mathrm{d}}\end{array}$ & $\begin{array}{l}\% 1,86 \\
\% 21,12 \\
\% 42,03 \\
\% 63,35 \\
\end{array}$ \\
\hline
\end{tabular}

Negatif Kontrol: Su (100 $\mu 1$ plak $\left.^{-1}\right)$ TA98 ve TA100 sușları için S9 yokluğunda negatif kontrol olarak kullanıldı.

Pozitif Kontroller: S9 varlı̆̆ında TA 98 sușu için 2-Aminofloren $\left(7,5 \mu \mathrm{g} \mathrm{plak}^{-1}\right)$, TA100 için sodyum azid (5 $\left.\mu \mathrm{g} \mathrm{plak}^{-1}\right)$ pozitif direkt mutajen olarak kullanıldı.

abcde Aynı sütundaki farklı harflere sahip gruplar arasındaki fark istatistiksel olarak önemlidir $(\mathrm{p}<0,05)$.

\section{SONUÇ VE ÖNERILER}

AMES, maddelerin kanserojen ve mutajenik potansiyelleri arasındaki ilişkiyi araştıran en önemli in vitro test sistemidir. Ancak son yirmi yılda yapılan araştırmalar, mutajenik olmayan kanserojenleri belirlemeye yöneliktir. Sonuç olarak bir test maddesinin genotoksik etkileri, bakteriyel gen mutasyon analizini takiben mikronükleus, komet, kardeş kromatid değişimi, kromozomal anormallikler ve transgenik siçan mutasyonu gibi in vitro ve in vivo test sistemleri ile araştırılmalı ve bu literatür verilerine dayanarak, ileriki çalışmalarımızda bu test sistemlerinde kenger bitkisi ile ilgili daha fazla çalışma yapılacaktır.

\section{TEȘEKKÜR}

Bu çalışma Kilis 7 Aralık Üniversitesi Bilimsel Araştırmalar Birimi tarafından desteklenmiştir (Proje No: 12472).

\section{KAYNAKLAR}

Al-kadhi, N.A., Abass, K.S. \& Abbas, Q.S. (2020). Ovarian activity improvement and antioxidant effects of Gundelia microcephala extract in oxidative stress rats. Eurasian Journal of Biosciences, 14(1), 747-756.
Asadi-Samani, M., Rafieian-Kopaei, M. \& Azimi, N. (2013). Gundelia: a systematic review of medicinal and molecular perspective. Pakistan Journal of Biological Sciences, 16(21), 12381247. DOI: 10.3923/pjbs.2013.1238.1247

Bauer, A.W., Kirby, W.M., Sherris, J.C. \& Turck, M. (1966). Antibiotic susceptibility testing by a standardized single disk method. Am. J. Clin. Pathol., 45(4), 493-496.

Ceylan, S., Cetin, S., Camadan, Y., Saral, O., Ozsen, O. \& Tutus, A. (2019). Antibacterial and antioxidant activities of traditional medicinal plants from the Erzurum region of Turkey. Irish Journal of Medical Science, 188(4), 1303-1309. DOI: 10.1007/s11845-019-01993-x

Darwish, R.M. \& Aburjai, T. (2010). Effect of ethnomedicinal plants used in folklore medicine in Jordan as antibiotic resistant inhibitors on $E$. coli. BMC Complement Altern. Med., 10, 9. DOI: 10.1186/1472-6882-10-9

Darwish, R.M., Aburjai, T., Al-Khalil, S. \& Mahafzah, A. (2002). Screening of antibiotic resistant inhibitors from local plant materials against two diffrent strains of S. aureus. J. Ethnopharmacol., 79, 359-364. DOI: $10.1016 / \mathrm{s} 0378$ 8741(01)00411-1

Ekmekci, N. (2010). Türkiye'deki bazl yöresel bal çeşitlerinin antimutajenik etkilerinin Salmonella/mikrozom (AMES) test sistemi ile araştırılması. Yükseklisans Tezi, Selçuk Üniversitesi Fen Bilimleri Enstitüsü. Konya, Türkiye, $58 \mathrm{~s}$ 
Haghi, G., Hatami, A. \& Arshi, R. (2011). Distribution of caffeic acid derivatives in Gundelia tournefortii L. Food chemistry, 124(3), 10291035. DOI: 10.1016/j.foodchem.2010.07.069

Karaaslan, Ö., Çöteli, E. \& Karataş, F. (2014). Kenger (Gundelia tournefortii) bitkisindeki A, E, C vitaminleri ile malondialdehit ve glutatyon miktarlarının araştırılması. EÜFBED-Fen Bilimleri Enstitüsü Dergisi, 7(2), 159-168.

Karataş, F. (2014). Kenger (Gundelia tournefortii) bitkisindeki vitaminler ile malondialdehit ve glutatyon miktarlarının araştırılması. Erzincan Üniversitesi Fen Bilimleri Enstitüsü Dergisi, 7(2), 159-168. DOI: 10.18185/eufbed.44500

Konak, M., Ateş, M. \& Şahan, Y. (2017). Yenlebilir yabani bitki Gundelia tournefortii'nin antioksidan özelliklerinin belirlenmesi, Journal of Agricultural Faculty of Uludag University, 31(2), 101-108.

Maron, D.M. \& Ames, B.N. (1983). Revised methods for the Salmonella Mutagenicity Test. Mutation. Research/Environmental Mutagenesis and Related Subjects, 113(3-4), 173-215. DOI: 10.1016/0165-1161(83)90010-9

Okcu, Z. \& Kaplan, B. (2018). Doğu Anadolu Bölgesinde Gıda Olarak Kullanılan Yabani Bitkiler. Türk Tarım-Gıda Bilim ve Teknoloji Dergisi, 6(3), 260265. DOI: 10.24925/turjaf.v6i3.260-265.1580

Özaltun, B., \& Daştan, T. (2019). Evaluation of antimicrobial activities and in vitro cytotoxic activities of Gundelia tournefortii L. Plant extracts. SDÜ Tip Fakültesi Dergisi, 26(4), 436442. DOI: $10.17343 /$ sdutfd.534049

Rafiee, L., Keshvari, M., Atar, A.M., Hamidzadeh, Z., Dashti, G.R., Rafieian-Kopaei, M. \& Asgary, S. (2017). Effect of Gundelia tournefortii L. on some cardiovascular risk factors in an animal model. Journal of Herbmed Pharmacology, 6(4), 191-195.

Sarac, N. (2015). Antioxidant, mutagenic, and antimutagenic activities of Tragopogon longirostis var. longirostis, an edible wild plant in Turkey. Indian Journal of Pharmacology, 47(4), 414. DOI: $10.4103 / 0253-7613.161267$

Saraç, H., Demirbaş, A., Daştan, S.D., Ataş, M., Çevik, Ö. \& Eruygur, N. (2019). Evaluation of nutrients and biological activities of Kenger (Gundellia tournefortii L.) seeds cultivated in Sivas province. Turkish Journal of Agriculture-Food Science and Technology, 7(2), 52-58. DOI: 10.24925/turjaf.v7isp2.52-58.3126

Uysal, A., Zengin, G., DurAk, Y. \& Aktümsek, A. (2016). Centaurea pterocaula özütlerinin antioksidan ve antimutajenik özellikleri ile enzim inhibitör potansiyellerinin incelenmesi. Marmara Pharmaceutical Journal, 20, 232-242. DOI: 10.12991/mpj.20162094922 